\title{
A teoria dos jogos competitivos de Norbert Elias como alternativa à leitura das políticas públicas de esporte e lazer no Brasil
}

CDD. 20.ed. 790.1

796.05
Fernando Augusto STAREPRAVO*

Juliano de SOUZA**

Wanderley MARCHI JUNIOR**

\section{Resumo}

0 mapeamento da produção científica recente sobre políticas públicas de esporte e lazer no Brasil nos apresentou um conjunto de produções, que em sua maioria são trabalhos em andamento, com o predomínio de exposições empiricas, com procedimentos metodológicos bem definidos, mas que, não apresentam um diálogo consistente com a literatura. Nos trabalhos que apresentam uma maior consistência teórica, os autores normalmente adotam uma postura de crítica ao neoliberalismo, entendendo que este modelo, em função dos interesses do capital, leva o Estado a intervir cada vez menos no âmbito social, repassando esta função a setores organizados da sociedade civil. Diante desse quadro ligeiramente evocado e na tentativa de ampliá-lo, procuramos apresentar neste artigo uma possibilidade de leitura das políticas públicas de esporte e lazer, amparados nos pressupostos teórico-metodológicos da Teoria dos Jogos Competitivos de Norbert Elias.

UnItermos: Políticas públicas; Esporte e lazer; Teoria dos jogos competitivos; Norbert Elias.

\section{Introdução}

O mapeamento da produção científica sobre políticas públicas de esporte e lazer no Brasil é um dos objetos de pesquisa que vem sendo priorizado em nossa trajetória acadêmica. Nesse sentido, nossas primeiras pesquisas indicavam que a produção de conhecimento na área de políticas públicas para o esporte e lazer estava predominantemente voltada ao relato de experiências (Starepravo, 2007; STAREPRAVO \& MEZZADRI, 2007).

Essa exposição empírica não se trata de uma condição exclusiva do subcampo ${ }^{1}$ científico/acadêmico das políticas públicas de esporte e lazer. Segundo MeLo (1999), a área de estudos das políticas públicas no Brasil se caracteriza por uma baixa capacidade de acumulação do conhecimento, fruto da proliferação horizontal de estudos de caso e da ausência de uma agenda de pesquisa. ARRETCHE (2003) corrobora esta posição, apontando que as abordagens teóricas e os métodos de investigação têm recebido uma atenção reduzida por parte dos estudiosos.

Mais recentemente, tendo como parâmetro as publicações no grupo de trabalho temático de Políticas Públicas no XV Congresso Brasileiro de
Ciências do Esporte, pudemos perceber um conjunto de produções, que em sua maioria são trabalhos em andamento, com o predomínio de exposições empíricas, com procedimentos metodológicos bem definidos, mas que, porém, não apresentam um diálogo consistente com a literatura. Nos trabalhos que apresentam uma maior consistência teórica, os autores normalmente adotam uma postura de crítica ao neoliberalismo, entendendo que este modelo, em função dos interesses do capital, leva o Estado a intervir cada vez menos no âmbito social, repassando esta função a setores organizados da sociedade civil (Starepravo, Nunes \& Marchi Junior, 2009).

Em termos de orientação teórica, essa se desenvolve no sentido do entendimento da macroestrutura econômica e social. Nestes casos, a apresentação dos dados empíri$\cos$ das pesquisas fica em segundo plano. A abordagem marxista nesta condição é predominante e a contingência dos processos políticos é deleteriamente desconsiderada (Starepravo, Nunes \& Marchi Junior, 2009).

Diante desse cenário ligeiramente evocado e na tentativa de ampliá-lo, procuramos apresentar no presente ensaio uma alternativa de leitura das 
políticas públicas de esporte e lazer, amparados nos pressupostos teórico-metodológicos da Teoria dos Jogos Competitivos de Norbert Elias. Mais especificamente problematizar como a reorientação do conceito de poder e a consideração da contingência dos processos políticos em Elias podem qualificar a discussão no subcampo científico/acadêmico das políticas públicas de esporte e lazer.

\section{A teoria dos jogos competitivos de Norbert Elias e as políticas pubblicas de esporte e lazer no Brasil}

O sociólogo alemão Norbert Elias em seu clássico texto "Introdução à Sociologia" (2005), chama a atenção para uma tradição científica de se estudar as partes de uma coletividade para se compreender o todo, o que designou como atomismo científico, que ainda sobreviveria na teoria, enquanto a prática científica já tomara um rumo diferente em muitos campos. Entende Elias (2005, p.78) que,

[...] quanto mais intimamente integrados forem os componentes de uma unidade compósita ou, por outras palavras, quanto mais alto for o grau de sua interdependência funcional, menos possível será explicar as propriedades dos últimos apenas em função das propriedades da primeira. Torna-se necessário não só explorar uma unidade compósita em termos de suas partes componentes, como também explorar o modo como esses componentes individuais se ligam uns aos outros, de modo a formarem uma unidade.

Este seria o motivo pelo qual a Sociologia não poderia se reduzir a agregar os conhecimentos da Psicologia, Biologia ou Física, compreendendo as partes, e estatisticamente, construir a compreensão do todo social. "[...] o seu campo de estudo - as configurações de seres humanos interdependentes - não se pode explicar se estudarmos os seres humanos isoladamente" (ELIAS, 2005, p.79). Em muitos casos, seria aconselhável o procedimento contrário, só se conseguindo compreender muitos dos comportamentos individuais se houvesse primeiro a compreensão das configurações que estabelecem uns com os outros.

Por outro lado, correr-se-ia o risco de adquirir uma perspectiva holística, onde se privilegiaria a totalidade como algo quase metafísico, sem maiores considerações às particularidades dos indivíduos que compõe o todo. Entre a alternativa atomista e a holística, ELIAS (2005) acredita existir outra possibilidade, onde os indivíduos, devido à sua interdependência e ao modo como suas ações e experiências se interpenetram, formam uma configuração, relativamente autônoma da ordem dominante.

Amparados nessas constatações de Elias, podemos dizer que as análises de políticas públicas de esporte e lazer que se constituem como relatos de experiências, bem como as que privilegiam os efeitos da macroestrutura econômica e social sobre as políticas, não nos satisfazem na explicação do referido fenômeno. Existe um espaço intermediário, chamado de configuração (nesse caso das políticas públicas de esporte e lazer), que deve ser mais bem interpretado, tanto na sua dinâmica interna, sob a lógica do Estado, como na sua relação com o restante da sociedade.

Nesse sentido, nos posicionamos na acepção de pensar as políticas públicas de esporte e lazer para além da política pública em si, o programa esportivo ou a iniciativa pública voltada a atender o cidadão no seu direito ao lazer como fenômenos estanques ou isolados. A política pública muitas vezes é apenas a parte mais visível de todo um processo desenvolvido num espaço social específico, que comporta disputas, relações, alianças, decisões estratégicas e também não planejadas. Em suma, compreender as políticas públicas de esporte e lazer requer mapear o espaço social onde esta é produzida, avançar no entendimento das relações entre os indivíduos, até finalmente compreender quais as políticas que foram efetivadas, aquelas que foram preteridas, as que obtiveram êxito e aquelas que não passaram de propostas (STAREPRAVO, 2011). Ou seja, precisamos estudar e compreender as configurações que se estabelecem em torno da formulação e implantação das políticas.

Para demonstrar como se estabelecem as configuraçóes humanas, Elias (2005, p.79), propóe,

[...] um tipo de experiência mental, por meio de uma série de modelos, o modo como se entrelaçam os fins e acções dos homens. Deste modo, os processos inerentemente complexos de interpenetração são temporariamente isolados e focados de perto, tornando-se mais facilmente compreensíveis.

Os modelos de competição (que podemos entender como modelos de relações sociais) são classificados em: competição primária sem regras, competição entre duas pessoas com regras, competição de muitas pessoas a um só nível, competição de dois níveis do tipo oligárquico, e, competição de dois níveis do tipo crescentemente 
democrático. Com exceção do primeiro tipo, os modelos se assemelham a jogos reais como xadrez, futebol, tênis ou tantos outros esportes. Representam a competição segundo regras, as quais podem variar em sua escala de presença e importância. "Todos os modelos se baseiam em duas ou mais pessoas que medem suas forças" (ELIAS, 2005, p.80), ou seja, na distribuição potencial de poder ao longo de uma configuração qualquer.

O equilíbrio de poder, segundo Elias (2005) constitui um elemento integral de todas as relaçôes humanas, as quais são, comumente, multipolares. Nesse caso, os modelos de jogos poderiam ajudar a "uma melhor compreensão do tal equilíbrio do poder, não como uma ocorrência extraordinária, mas como uma ocorrência cotidiana” (EliAs, 2005, p.80). Elias entende que ninguém vem ao mundo desprovido de poder, pois este é um elemento básico nas relações humanas. Ocorre que como por vezes o desequilíbrio de poder é muito grande, algumas perspectivas teóricas acabam reificando o poder em suas análises. No entanto, como bem adverte EliAs (2005, p.80, grifo do autor), "o poder não é um amuleto que um indivíduo possua e outro não, é uma característica estrutural das relações humanas - de todas as relações humanas".

Portanto, e segundo a matriz teórica eliasiana recuperada nesse artigo, é importante conduzir uma pesquisa, especialmente quando trata de políticas públicas, compreendendo e direcionando o olhar para as dimensões estruturais do poder nas relaçóes humanas. Nesse caso, precisamos desmistificar o poder. Ele está presente sim em todas as relações humanas, mesmo quando o desequilíbrio de poder é muito grande, como muitas vezes observamos na relação entre agentes do Estado e a sociedade. Um exemplo recente do campo esportivo que exemplifica tal situação é a organização da Copa do Mundo de Futebol masculino, a ser realizada no Brasil em 2014. Existem agentes públicos que nitidamente concentraram demasiadamente o poder de decisão em relação aos rumos da organização do mundial. Nesse caso, os demais indivíduos se sentem desprovidos de poder perante tal situação. Todavia, toda e qualquer pessoa possui um potencial de poder, que pode ser maximizado, por exemplo, através de iniciativas coletivas.

Em relação ao entendimento do poder, ELIAS (2005) admite que os fenômenos sociais a que este conceito se refere são extremamente complexos e, portanto, de difícil compreensão. Além disso, a noção de poder é permeada por alguns "mitos", como "o poder é suspeito [...], o poder parece imoral [...], e a névoa de medo e desconfiança que se apega a este conceito transfere-se compreensivelmente para a sua utilização numa teoria científica” (EliAS, 2005, p.101). A superação mais adequada para este entrave, segundo EliAs (2005), seria considerar o poder, de modo inequívoco, como característica estrutural de uma relação, que a penetra totalmente; uma característica estrutural que não é necessariamente nem boa e nem má, mas que inevitavelmente se faz presente nos vínculos de interdependência entre os indivíduos e grupos, visto que cada agente, em maior ou menor grau, depende de seus pares.

Dependemos dos outros; os outros dependem de nós. Na medida em que somos mais dependentes dos outros do que eles são de nós, em que somos mais dirigidos pelos outros do que eles são por nós, estes têm poder sobre nós, quer nos tenhamos tornado dependentes deles pela utilização que fizeram da força bruta ou pela necessidade de dinheiro, de cura, de estatuto, de uma carreira ou simplesmente de estímulo (Elias, 2005, p.101).

Nesse sentido, os modelos de jogos serviriam ainda para corrigir o hábito de utilizar o conceito de forma estática, lembrando que todas as relaçōes humanas, tais como os jogos humanos, são processos. EliAs (2005) chama a atenção para a tendência de personificação ou reificação das interdependências humanas, levando a acreditar que há alguém que detém o poder, e assim as pessoas sentem a pressão do poder. "[...] inventamos sempre alguém que o exerça, ou um tipo de entidade sobre-humana como seja a "natureza» ou a «sociedade» nas quais o poder reside" (ELIAS, 2005, p.102). Isso é especialmente válido quando das investigações acerca do Estado. O Estado seria um ente "superpoderoso", "sobrehumano", que gozaria de extremo poder e o utilizaria em prol de interesses nem sempre tão claros. Isso ocorre, notadamente, no subcampo político/burocrático do esporte e lazer, uma vez que a relação entre sociedade e Estado nesse campo historicamente foi marcada por um processo de submissão do primeiro em relação ao segundo, onde estabeleceu-se uma dependência tutelar dos indivíduos em relação ao Estado (STAREPRAVO, 2011). Os modelos reorientariam o entendimento do poder, de modo a compreender a natureza das tarefas ao se fazer Sociologia. Reitera o autor:

Os modelos de jogo ajudam a mostrar como os problemas sociológicos se tornam mais claros e como é mais fácil lidar com eles se os reorganizarmos em termos de equilíbrio, mais do que em termos reificantes. Conceitos de equilíbrio são muito mais adequados ao que pode ser realmente observado quando se investigam as relações funcionais que os seres humanos interdependentes mantêm uns com os outros, do que os conceitos modelados em objectos imóveis (ELIAS, 2005, p.81). 
Ora, por mais que a relação entre Estado e sociedade tenha sido estruturada numa relação de poder muito desproporcional em favor do Estado, o que precisaríamos averiguar é de que forma mantevese essa estrutura desde a década de 40 até os dias atuais. As tensões surgidas foram dissipadas por acomodações políticas, liberação de recursos financeiros às modalidades esportivas, relaçôes paternalistas, assistencialistas, entre outros. Com isso, a balança de poder se manteve estável, todavia não livre de tensões e contradiçōes. Cabe aos cientistas sociais, especialmente os empenhados no estudo das políticas públicas de esporte e lazer no Brasil, analisar quais os fatores determinantes para a estabilidade da balança de poder numa situação tão desproporcional, e não apenas o papel de apontar o Estado como "o" detentor do poder.

Nesse caso, fazemos uso da Teoria dos Jogos Competitivos de Elias, como uma ferramenta para clarificar o olhar sobre as relações humanas, notadamente as que envolvem as políticas públicas de esporte e lazer no Brasil, a partir dos pressupostos já levantados. O primeiro dos modelos propostos por EliAs (2005, p.82), a competição (ou relaçōes sociais) primária sem regras, pode "servir como advertência de que é perfeitamente possível estruturar as relações sociais entre os indivíduos, mesmo que estas se desenrolem sem regras", como em alguns casos de guerras, rebeliōes ou massacres.

Nestes casos, assim como em outras circunstâncias sociais semelhantes, "um antagonismo razoavelmente estável revela-se como forma de interdependência funcional" (EliAs 2005, p.83). Ou seja, as estruturas internas de cada grupo e a tomada de decisão se dão de acordo com o que se espera que o outro grupo faça depois. Um grupo depende do outro e da jogada do outro. Não é possível neste caso, "explicar as acçóes, os planos e os objectivos de qualquer um dos dois grupos se eles forem conceptualizados como decisões, planos e objectivos comuns a cada grupo, considerado por si mesmo, independente do outro grupo" (ELIAS, 2005, p.84). Só é possível, portanto, explicar as relaçōes entre os grupos, se considerar as forças coercivas que os grupos exercem um sobre o outro, devido a sua interdependência e função bilateral que desempenham como inimigos ou oponentes.

Dito em outros termos, mesmo não havendo regras comuns, existe, de fato, uma interdependência entre os grupos (que gera uma regra quase que implícita na relação) - uma interpenetração onde a sequência de açôes dos grupos depende do adversário, o que, por conseguinte, revela que o estudo das ações individuais, configuracionalmente falando, não tem sentido e relevância. Quanto a isso, ELIAS (2005, p.87) reforça que: "Embora a interpenetração de ambos os lados seja, no decorrer do tempo, um processo sem normas, é, no entanto um processo com uma estrutura nítida podendo esta ser analisada e explicada”. Portanto, mesmo em casos mais simples e primitivos de relação há a possibilidade de análises que extrapolam a mera explicação causal.

A competição primária apresenta-se como um caso de fronteira, onde um dos lados tem como privar o outro, não só de suas funções sociais, mas de sua própria vida. Esta situação leva, além da compreensão da própria relação, ao entendimento de como as pessoas foram e são capazes de regular e manter suas interdependências sem precisar recorrer a esta última saída para resolução de suas tensões e conflitos (ELIAS, $2005)^{2}$. Esse questionamento, por sua vez, nos remete a formas mais sofisticadas de relaçôes humanas, onde existe a presença de regras para mediar as relaçóes interdependentes. Esse primeiro modelo apresentado não nos parece adequado ao entendimento e estudo das políticas públicas de esporte e lazer, já que mesmo que por vezes haja uma subversão às regras, existem normas que regulam a relação entre Estado e sociedade no âmbito esportivo, dentre elas as constituições estaduais e federal, as legislações infraconstitucionais e demais normas. Apresentar esse modelo serve como meio de exemplificar a interdependência entre os seres humanos, bem como diferenciar esse modelo mais simples de situaçôes e jogos sociais mais complexos.

$\mathrm{Na}$ competição (ou relação social) entre duas pessoas com regras, ELIAS (2005) destaca que em todas as relações sociais os participantes têm que exercer um controle mútuo, pois os dois lados possuem algum potencial de poder. No entanto, como um dos lados tem uma proporção de poder maior, este possui um relativo controle sobre seu adversário, bem como um alto grau de controle sobre o jogo. Ao passo que esta balança de poder entre os rivais se equilibra, menos presente estará o controle de um deles sobre o jogo. Em outras palavras, "à medida que a desigualdade de forças dos dois jogadores diminui, resultará da interpenetração de jogadas de duas pessoas individuais, um processo de jogo que nenhuma delas planejou" (ELIAS, 2005, p.89, grifos do autor). Esse modelo nos parece pertinente à análise da relação entre os indivíduos de determinadas estruturas estatais. O Ministério do Esporte, por exemplo, comporta uma série de indivíduos em seus cargos de primeiro e segundo escalão que nitidamente apresentam interesses antagônicos, haja vista sua 
origem partidária ou ideológica distinta. Uma análise do tipo de relação (ou competição) travada entre esses indivíduos a partir desse modelo dos jogos nos parece profícua. O mesmo podendo ser observado em outras instituições que compõem ou se relacionam com o Estado no campo esportivo. Análises com essas características podem ser observadas nos trabalhos de Starepravo (2011) e Martins (2004).

Já a competição (ou relação social) de muitas pessoas a um só nível, pressupõe a presença de vários jogadores numa configuração em comum. Segundo ELIAS (2005, p.90), essa dinâmica “[...] basicamente é uma série de jogos para duas pessoas, tendo cada jogo o seu equilíbrio de poder e processando-se de um modo próprio". A complexidade é maior, pois envolve vários jogos e vários indivíduos que jogam em múltiplas situações. $\mathrm{Na}$ configuração, um dos jogadores pode ter um potencial de poder superior aos demais, o que lhe dá controle sobre seus adversários individuais e, por conseguinte, a cada um dos jogos estabelecidos. A balança de poder nesse caso pode ficar muito desproporcional em função desse jogador, ou ao menos o mesmo pode demonstrar um olhar privilegiado sobre os múltiplos jogos.

Porém, se estes adversários com menor potencial de poder se unirem contra o adversário de maior poder, a balança do poder e o controle sobre o jogo tendem a se alterar. Neste caso, "[...] há muito menos certeza sobre o controle e planejamento do jogo e, portanto, menos certeza na previsão do seu resultado" (Elias, 2005, p.90). Se o grupo de adversários mais fracos não tiver tensões internas fortes, isto pode constituir um fato ao seu favor, que no confronto com o adversário mais forte pode resultar em mudanças na configuração do poder. Essa reflexão parece profícua na discussão sobre descentralização e participação popular nas políticas públicas de esporte e lazer, realizada entre outros por Silva (2011), BeHmoiras, Liáo Junior, Sampaio e Figueiredo (2011), Athayde e Mascarenhas (2011).

No caso dos adversários buscarem parcerias, que equilibram em demasia a balança do poder, uma previsão em relação ao resultado do jogo é menos provável. Assim como na competição sem regras, a ação de cada um dos grupos dependerá muito do outro grupo e só poderá ser compreendida a partir do olhar sobre ambos os grupos e suas relações.

Quando as pesquisas da área das políticas públicas de esporte e lazer já partem do pressuposto de que todas as políticas apresentam uma regularidade, no sentido de cumprirem a cartilha do neoliberalismo e buscarem a desresponsabilização do Estado, perde-se a oportunidade de buscar elementos nas relações humanas construídas a partir da elaboração e implementação de políticas públicas, que expliquem o resultado a partir de um processo cego, diferente do que cada indivíduo isoladamente pode ter almejado no início do processo.

Ao passo que o número de jogadores na configuração aumenta demasiadamente, "tornar-se-á cada vez mais difícil ao jogador a constituição de uma representação mental do decurso do jogo e da sua figuração" (ELIAS, 2005, p.92). O jogador individual perde sua referência, ficando cada vez mais obscura a leitura do jogo, a partir da qual ela toma suas decisões. Segundo Elias (2005, p.92, grifo do autor): "[...] à medida que cresce o número de jogadores, o jogador individual não só começa a achar o jogo cada vez mais opaco e incontrolável como também se torna consciente da sua impossibilidade em compreendê-lo e controlá-lo". Nesse caso, o controle sobre as açóes e ao percurso do jogo fica prejudicado, tornando-se o jogo cada vez mais imprevisível. Além disso, neste momento tende-se a crescer a pressão dos jogadores para reorganização do jogo, de modo que se abrem novas possibilidades configuracionais, que ELIAS (2005) aborda de forma detalhada.

No modelo de competição (ou relações sociais) de dois níveis do tipo oligárquico, Elias (2005) destaca que a pressão exercida pelo aumento do número de jogadores, pode ocasionar mudanças no interior da configuração, onde "um grupo em que os indivíduos jogam com os outros a um mesmo nível, pode converter-se num grupo de jogadores de «dois níveis»" (ELIAS, 2005, p.93). Todos os jogadores se mantêm interdependentes, mas não jogam mais diretamente uns com os outros. A função de jogar diretamente é delegada a representantes (líderes, governos, elites, etc.), que coordenam o jogo. Este segundo grupo, vinculado ao primeiro, se relaciona e de alguma forma representa o primeiro. Vejamos: Cada um dos níveis é mutuamente dependente possuindo reciprocamente diferentes oportunidades de poder, correspondentes ao grau da sua dependência mútua. Mas a distribuição de poder entre os indivíduos do primeiro e do segundo níveis pode variar muitíssimo. As diferenças de poder entre eles podem ser muito grandes - em favor dos últimos - e podem tornar-se cada vez mais pequenas (ELIAS, 2005, p.93-94).

É importante destacar que apesar do segundo grupo, que representa o primeiro, possuir um maior potencial de poder, este não constitui uma relação a um só nível com o outro grupo representante, haja vista que está ligado, de forma interdependente, ao grupo que representa. Além disso, por mais que esse grupo 
tenha uma visão e entendimento privilegiado do jogo, não o pode controlar completamente. Nesse caso, a configuração do jogo e dos jogadores possui um grau de complexidade que impede qualquer indivíduo de usar a sua superioridade, orientando o jogo na direção das suas próprias metas e desejos. Há jogadas tanto dentro como para fora da teia de jogadores interdependentes, onde há alianças, inimizades, cooperação e rivalidades em diferentes níveis (Elias, 2005). Várias dessas características apontadas por Elias são recorrentes nas análises de políticas públicas, havendo vários indícios sobre a coerência na utilização desse modelo de jogo para interpretá-las, especialmente quando se discute a disparidade entre os grupos políticos representantes e a população que os elege, apontando que normalmente a ação pública se configura em função dos interesses de grupos minoritários detentores dos meios de produção. Nesse sentido, ver Silva (2011) e Bernardo, Silva, Morais e COUTINHo (2011).

Em uma situação mais antiga e oligárquica, segundo Elias (2005), o equilíbrio de poder a favor do nível mais elevado é muito desproporcional, rígido e estável. Porém, a interdependência entre os níveis impõem limitaçōes a cada jogador, mesmo no nível mais elevado. Estudos que privilegiam apenas o grupo representante, mesmo em casos oligárquicos, desconsiderando os grupos representados, se mostram limitados. As três ou quatro formas de equilíbrio de poder, interdependentes num modelo oligárquico em dois níveis, tornam possíveis inúmeras possibilidades dentro do jogo, o que só pode ser mais bem compreendido através da análise dos grupos e da relação entre os grupos.

No desenvolvimento histórico das políticas públicas de esporte e lazer pode-se verificar a predominância de situações onde o modelo de competição oligárquico seria pertinente à análise. Desde as primeiras regulamentaçôes da atuação do Estado no âmbito esportivo, ainda na década de 40, estabeleceu-se um modelo de concentração de poder nas mãos do Estado, estabelecendo uma relação de dependência tutelar do campo esportivo para com o Estado. Esse quadro se desenvolveu em grande parte do século XX, havendo uma mudança significativa apenas na segunda metade da década de 80, quando a Constituição Federal e demais legislações esportivas complementares estabeleceram o fim dessa relação tutelar e subordinada.

Em contrapartida, há casos em que o poder do grupo inferior cresce de tal forma, que outro modelo, o de competição (ou relações sociais) de dois níveis do tipo crescentemente democrático, parece ser mais adequado. Ressalta o autor alemão: "[...] Se diminuírem as diferenças de poder entre os dois grupos, reduzindo-se as suas desigualdades, então o equilíbrio de poder tornar-se-á mais flexível e elástico" (ELIAS, 2005, p.96). Quando os jogadores do nível mais baixo ficam mais poderosos, as jogadas dentro do grupo representante cairão sobre o controle de uma configuração muito mais complexa, pois o controle sobre os jogadores e o próprio jogo é menor.

Elias destaca que geralmente o grupo de jogadores do nível mais baixo exerce apenas uma influência indireta e latente sobre os jogadores do nível mais alto, fruto aparente de sua desorganização. Entretanto, se as diferenças de poder diminuírem substancialmente, tende a mudar as funçōes entre os jogadores do nível mais alto e posteriormente os próprios jogadores. A pressão vinda de baixo acaba sendo tão forte, que a postura de decidir pelo outro grupo, com controle aparente sobre o jogo, passa a ser de uma forma mais aberta e precisa, condicionada em função da postura de funcionários, porta-vozes ou representantes do grupo mais baixo (Elias, 2005). Nesse caso, se a área de esporte e lazer apresentasse uma boa capacidade técnica nos estratos mais baixos da burocracia, muitas das tomadas de decisão das camadas superiores em favor do acúmulo de capital político poderiam ser tensionadas e revertidas por aqueles que deteriam um maior potencial de poder em função do capital cultural específico. Todavia essa é uma realidade ainda distante no contexto brasileiro.

Diferente do modelo anterior, no modelo de jogo de dois níveis do tipo crescentemente democrático, os jogadores do nível inferior, dada sua conquista de poder, são importantes sobremaneira ao desenvolvimento do jogo. A estratégia de cada um dos jogadores do nível mais alto, nas suas relaçôes com os grupos de nível mais baixo que representa, tornase um aspecto do jogo tão importante como a sua estratégia relativa aos outros jogadores do mesmo nível. À medida que a distribuição de poder se torna menos desigual e mais difusa, maior será o estado de tensão permanente dos jogadores, o que torna o jogo mais difícil de ser controlado (Elias, 2005). Discussões da área de políticas públicas sobre participação popular e gestão democrática, como as recentes Conferências Nacionais do Esporte ou a criação de conselhos municipais e estaduais de esporte e lazer ${ }^{3}$, teriam nesse modelo um aliado interessante na compreensão das dinâmicas sociais.

Este processo leva os jogadores a mudar sua concepção do jogo, passando de um entendimento que o jogo vai tomando forma a partir das jogadas individuais, para uma tendência a produzir conceitos e discursos impessoais que expressam a lógica do jogo, 
cada vez mais complexo e interdependente. De acordo com Elias (2005, p.99): "Como o jogo não pode ser controlado pelos jogadores é facilmente concebido como uma espécie de entidade "super-humana»", o que, com efeito, se constitui e se caracteriza como uma consequência da dependência mútua entre os jogadores, suas posições, tensões e conflitos”.

Como síntese do que até aqui foi dito, entendemos que os modelos de jogos competitivos recuperados e apresentados rapidamente nesse ensaio contribuem, de forma didática e de acordo com cada uma das situações, ao melhor entendimento e compreensão das relações entre pessoas, indivíduos ou agentes interdependentes, que jogam em função dos outros jogadores e em conformidade com o movimento da balança do poder, inclusive em se tratando da formulação, implementação e avaliação das políticas públicas de esporte e lazer.

A produção científica sobre políticas públicas de esporte e lazer no Brasil atualmente se ramifica em duas perspectivas principais. De um lado, temos o olhar marxista que privilegia as condições macroestruturais da sociedade e como as mesmas atingem as políticas de esporte e lazer. De outro, temos a exposição de relatos ou dados empíricos que não estabelecem um diálogo mais efetivo e consistente com as teorias.

Como alternativa a esse embate, procuramos apresentar no presente artigo, a possibilidade da apropriação de alguns conceitos de Elias e seu modelo de jogos competitivos, como possibilidades para se estudar a área. Em síntese, percebemos que a arquitetura teórica trabalhada pelo autor nos possibilita estudar as políticas públicas de esporte e lazer contemplando as interdependências sociais e o poder como uma característica estrutural das relaçôes humanas.

Além disso, a abordagem de Elias conserva como imperativo o fato de que as interdependências humanas são mutáveis e se apresentam de diversas formas, sendo necessárias estudá-las, considerando especialmente as contigências dos processos políticos.

Finalmente, destacamos que os modelos de jogos de Elias podem constituir uma rigorosa e consistente ferramenta metodológica para compreensão do mundo social, bem como para o aprofundamento do entendimento dos fenômenos sociais, no nosso caso específico, do universo das políticas públicas de esporte e lazer.

\title{
Notas
}

1. A caracterização do campo ou subcampo se dá através da definição do espaço social onde se encontram fixadas as posições e os agentes sociais movimentam-se objetivando conquistas. Outra característica do campo é seu objeto de disputa e seus interesses específicos. Em outras palavras, o campo é definido como "o lócus onde se trava uma luta concorrencial entre os atores em torno de interesses específicos que caracterizam a área em questão” (ORTIZ, 1994, p.19). Além disso, para a existência do campo, devem existir, em seu interior, além dos objetos de interesse e disputa, pessoas (agentes) dotadas de "habitus" que identifiquem e legitimem as leis imanentes ao jogo (MARCHI JunIOR, 2001).

2. Isso representa um dos pontos centrais da empreitada intelectual de Elias ao buscar explicar a sociedade a partir de um Processo Civilizador dos Costumes (Elias, 1993).

3. Ver Araújo, Fernandes, Dominici, Vieira, Sousa, Cunha Filho, Pereira e Jara (2011), Starepravo (2007), Castelan (2011), Guedes, Lins, Antonio, Miguel, Dangui e Starepravo (2011), entre outros.

\begin{abstract}
The competitive game theory of Norbert Elias as alternative to the reading of public policies for sport and leisure in Brazil

The mapping of recent scientific literature on public policy of sport and leisure in Brazil has presented a set of productions, which are mostly works in progress, with the predominance of empirical exhibitions, with well-defined methodological procedures, but they have not been presented a consistent dialogue with the literature. In studies showing greater theoretical consistency, the authors usually adopt a critical stance to neoliberalism, understanding that this model, based on the interests of capital, leads the State to intervene less in the social, transferring this function to civil society organized sectors. Given
\end{abstract}


this situation slightly raised and trying to expand it, we present in this article a possibility of reading the public policy of sport and leisure, supported the theoretical and methodological assumptions of Norbert Elias' Game Theory Competitive.

UnIterms: Public policies; Sport and leisure; Competitive game theory; Norbert Elias.

\section{Resumen}

La teoría de los juegos competitivos de Norbert Elias como una alternativa a la lectura de las políticas de deporte y ocio en Brasil

La cartografía de la literatura científica reciente sobre la política pública del deporte y el ocio en Brasil ha presentado una serie de producciones, que son en su mayoría obras en curso, con el predominio de exposiciones empíricas, procedimientos metodológicos bien definidos, pero que no presentan un diálogo constante con la literatura. En los estudios que tienen una mayor consistencia teórica, los autores suelen adoptar una postura crítica al neoliberalismo, entendiendo que este modelo, basado en los intereses del capital, lleva al Estado a intervenir cada vez menos en la vida social, la transferencia de esta función a los sectores organizados sociedad civil. Ante esta situación ligeramente elevada y tratar de ampliar, presentamos en este artículo la posibilidad de leer la política pública del deporte y el ocio, con el apoyo de los supuestos teóricos y metodológicos de la Teoría de los Juegos Competitivos de Norbert Elias.

Palabras clave: Políticas públicas; Deporte y ocio; Teoria de los juegos competitivos; Norbert Elias.

\section{Referências}

ARAÚJO, S.M.; FERNANDES, C.A.; DOMINICI, K.R.; VIEIRA, A.P.; SOUSA, J.C.; CUNHA FILHO, A.S.; PEREIRA, C.F.; JARA, I.C. Participação popular e controle social na gestão pública: um estudo dos Conselhos Estaduais de Esporte na Região Nordeste do Brasil. In: CONGRESSO BRASILEIRO DE CIÊNCIAS DO ESPORTE, 27.; CONGRESSO INTERNACIONAL DE CIÊNCIAS DO ESPORTE, 4., 2011, Porto Alegre. Anais... Porto Alegre: CBCE, 2011. ARRETCHE, M.T.S. Dossiê agenda de pesquisas em políticas públicas. Revista Brasileira de Ciências Sociais, São Paulo, v.18, n.51, p.7-10, 2003.

ATHAYDE, P.A.; MASCARENHAS, F. Descentralização de políticas sociais: limites para a consolidação de uma gestão democrática do Programa Segundo Tempo. In: CONGRESSO BRASILEIRO DE CIÊNCIAS DO ESPORTE, 27.; CONGRESSO INTERNACIONAL DE CIÊNCIAS DO ESPORTE, 4., 2011, Porto Alegre. Anais... Porto Alegre: CBCE, 2011.

BEHMOIRAS, D.C.; LIÁO JUNIOR, R.; SAMPAIO, J.O.; FIGUEIREDO, P.O.F.N. Fórum popular e permanente de esporte e lazer: a luta pela hegemonia e a perspectiva da socialização da política no DF. In: CONGRESSO BRASILEIRO DE CIÊNCIAS DO ESPORTE, 27.; CONGRESSO INTERNACIONAL DE CIÊNCIAS DO ESPORTE, 4., 2011, Porto Alegre. Anais... Porto Alegre: CBCE, 2011.

BERNARDO, E.C.; SILVA, C.S.; MORAIS, A.M.; COUTINHO, T.O. Lei de Incentivo ao Esporte (11.438/2006), Estado e democracia: reflexões sobre a sociedade de classes. In: CONGRESSO BRASILEIRO DE CIÊNCIAS DO ESPORTE, 27.; CONGRESSO INTERNACIONAL DE CIÊNCIAS DO ESPORTE, 4., 2011, Porto Alegre. Anais... Porto Alegre: CBCE, 2011. CASTELAN, L.P. As Conferências Nacionais do Esporte na configuração da política esportiva e de lazer do governo Lula (2003-2010). In: CONGRESSO BRASILEIRO DE CIÊNCIAS DO ESPORTE, 27.; CONGRESSO INTERNACIONAL DE CIÊNCIAS DO ESPORTE, 4., 2011, Porto Alegre. Anais... Porto Alegre: CBCE, 2011.

ELIAS, N. O processo civilizador. Rio de Janeiro: Zahar, 1993. v.1-2.

Introdução à sociologia. Tradução de Maria Luísa Ribeiro Ferreira. São Paulo: Martins Fontes, 2005.

GUEDES, K.N.A.A.; LINS, M.G.; ANTONIO, M.W.; MIGUEL, R.G.; DANGUI, J.; STEREPRAVO, F.A. Reflexōes sobre a $3^{\text {a }}$ Conferência Nacional de Esporte. In: CONGRESSO BRASILEIRO DE CIÊNCIAS DO ESPORTE, 27.; CONGRESSO INTERNACIONAL DE CIÊNCIAS DO ESPORTE, 4., 2011, Porto Alegre. Anais... Porto Alegre: CBCE, 2011.

664 • Rev. bras. Educ. Fís. Esporte, São Paulo, v.26, n.4, p.657-65, out./dez. 2012 
MARCHI JUNIOR, W. “Sacando” o voleibol: do amadorismo à espetacularização da modalidade no Brasil (1970-2000). 2001. Tese (Doutorado em Educação Física) - Faculdade de Educação Física, Universidade Estadual de Campinas, Campinas, 2001. MARTINS, D.J.Q. A formulação e a implementação das políticas públicas no campo do esporte no Estado do Paraná entre 1987 e 2004. 2004. Dissertação (Mestrado em Educação Física) - Universidade Federal do Paraná, Curitiba, 2004. MELO, M.A. Estado, governo e políticas públicas. In: MICELI, S. (Org.). O que ler na ciência social brasileira (19701995). São Paulo: Sumaré/Anpocs/Capes, 1999. v.3: Ciência política, p.59-100.

ORTIZ, R. Pierre Bourdieu. São Paulo: Ática, 1994.

SILVA, S.R. A pseudoparticipação nas políticas de conferência de esporte e lazer: o esporte escolar na perspectiva de alto rendimento. In: CONGRESSO BRASILEIRO DE CIÊNCIAS DO ESPORTE, 27.; CONGRESSO INTERNACIONAL DE CIÊNCIAS DO ESPORTE, 4., 2011, Porto Alegre. Anais... Porto Alegre: CBCE, 2011.

STAREPRAVO, F.A. Políticas públicas para o esporte e lazer: conselhos municipais de esporte e lazer e outras formas de participação direta. In: CONGRESSO BRASILEIRO DE CIÊNCIAS DO ESPORTE, 15.; CONGRESSO INTERNACIONAL DE CIÊNCIAS DO ESPORTE, 2., 2007, Recife. Anais... Recife: CBCE, 2007.

Políticas públicas de esporte e lazer no Brasil: aproximações, intersecções, rupturas e distanciamentos entre os subcampos político/burocrático e científico/acadêmico. 2011. Tese (Doutorado em Educação Física) - Universidade Federal do Paraná, Curitiba, 2011.

STAREPRAVO, F.; MEZZADRI, F.M. Algumas contribuições de Pierre Bourdieu e Norbert Elias à discussão de políticas públicas para o esporte e lazer. In: SIMPÓSIO INTERNACIONAL PROCESSO CIVILIZADOR, 10., 2007, Campinas. Anais... Campinas: FEF/UNICAMP, 2007.

STAREPRAVO, F.A.; NUNES, R.J.S.; MARCHI JUNIOR, W. Agenda de pesquisa em políticas públicas de esporte e lazer: uma leitura a partir do GTT de Políticas Públicas no XV Congresso Brasileiro de Ciências do Esporte. In: CONGRESSO BRASILEIRO DE CIÊNCIAS DO ESPORTE, 26.; CONGRESSO INTERNACIONAL DE CIÊNCIAS DO ESPORTE, 3., 2009, Salvador. Anais... Salvador: CBCE, 2009.

\begin{tabular}{r|r} 
ENDEREço & \\
Fernando Augusto Starepravo & Recebido para publicação: 04/08/2011 \\
Departamento de Educação Física & 1a. Revisão: 07/02/2012 \\
Universidade Estadual de Maringá & 2a. Revisão: 14/05/2012 \\
Av. Colombo, 5.790 - Campus Universitário & 2a. \\
87020-900 - Maringá - PR - BRASIL & Aceito: 25/05/2012 \\
e-mail: fernando.starepravo@hotmail.com & \\
&
\end{tabular}

